\title{
OXYGEN REFINED FERROALLOYS
}

Successful in steelmaking, oxygen top-blowing techniques are now being employed for the refining of ferrochrome. This may be the beginning of the wide-spread use of oxygen in the ferroalloys industry.

$T^{2}$ aking its cue from the LD, basic oxygen steelmaking process, the ferroalloy industry has begun utilizing oxygen for the refining of ferrochrome.

For Union Carbide Metals Co., the development of oxygen refined ferrochrome is the culmination of several years of experimental work at the Marietta, Ohio, plant. Starting material is an intermediategrade of ferrochrome produced in a one-stage smelting operation in submerged arc furnaces. Analysis of this material is approx as follows: $68-71$ pct Cr, 5-6 pet C, 2-3 pct Si, and 0.07 pct $\mathrm{S}$. Oxygen refining reduces carbon to a max of 4.25 pct, silicon to a max of 1.00 pct, and sulfur to a max of 0.03 pct, with chromium between 58 and 65 pct.

In the new process, ferrochrome, tapped from a submerged-arc furnace into ladles, is transported to the oxygen refining post where a hood is placed over the ladle. A vertical, water-cooled copper lance is lowered into position over the ladle containing from 8000 to $10,000 \mathrm{lb}$ of ferroalloy. Blowing commercially-pure oxygen at the rate of less than 1000 $\mathrm{cu} \mathrm{ft}$ per min requires from 30 to $40 \mathrm{~min}$. During the cycle, lime is added to form a slag. Considerable fume is formed and carried out through the hood into a dust-catching installation. The overall cycle, including pouring the refined ferrochrome into chills, is a matter of about $1 \mathrm{hr}$. The slag, because of its high chrome content, is returned to the submerged-arc smelting furnaces.

Another firm is active in this same field. At the Beverly plant of Interlake Iron Corp. oxygen-refined ferrochrome has been in commercial production since early 1960 with some 2500 tons made thus far. Their operation is quite similar to that of Union Carbide with carbon reduced from 5.5 or 6 pet to a max of 4.25 pet and silicon to 1 pet max. While marketing this product, Interlake is also producing a max 2-pct silicon ferrochrome which is the result of deoxidizing the melt with chrome silicide in order to recover chrome which would otherwise be lost in the slag unless it were resmelted.

\section{Advantages}

Refined ferrochrome is a low-cost source of chromium charge material for stainless steels. It is of particular interest to stainless producers because its comparatively low carbon and silicon contents allow large additions of chromium to the base charge. It is a lower cost material, because it is less costly to reduce the carbon and silicon contents of ferrochrome by oxygen blowing than it is to produce the same grade of material in a double-stage furnace operation.

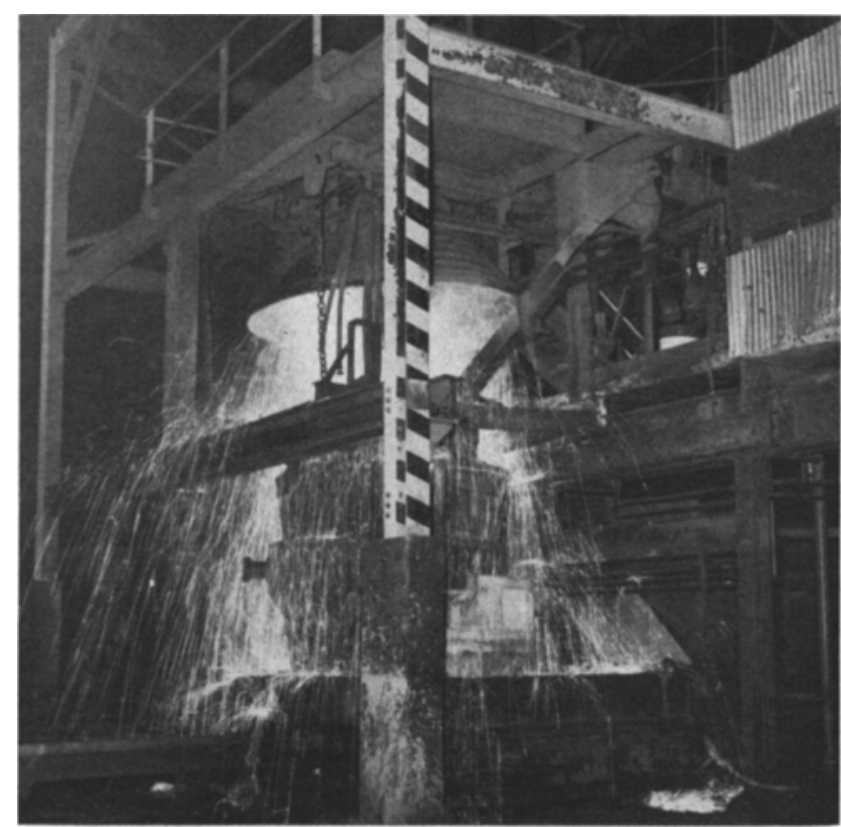

Oxygen refining ferrochrome at the Marietta, Ohio, plant of Union Carbide Metals Co.

Oxygen injection causes intense agitation of the molten charge at elevated temperatures which serves to homogenize the melt and remove deleterious gas. The result is a more uniform, more dense product. Furthermore, the higher temperatures and added time in the molten state allow for the removal of impurities. Finally, in oxygen-blown ferrochrome, reactive elements, such as titanium, are substantially removed. The overall result is a better product.

\section{General application}

These reasons should add up to a general adoption of oxygen refining for the production of lower-carbon grades of ferrochrome. And this appears to be the case. In addition to Union Carbide and Interlake, other firms are also moving into this same area of oxygen refining. Vanadium Corp. of America has been conducting extensive tests and is reported ready to exploit the practical aspects of this process.

Thus, it appears that oxygen refining of ferrochrome will be adopted on an industry-wide basis. The introduction of oxygen to ferrochrome production bodes well for a far wider application of oxygen to other ferroalloys. The door is opening, and oxygen may begin to revolutionize the ferroalloy industry as it has done with the steel industry.

F. Weston Starratt 